\title{
The Contextual Analysis of Written Communication in Fraud and Non-fraud Companies: Comparing Enron and Facebook Communications
}

\author{
Subash Adhikari* \\ University of South Dakota \\ G. Stevenson Smith \\ University of South Dakota
}

\begin{abstract}
:
Written texts can reveal the personality traits of the authors of those documents. Beyond the differences in writing styles of individuals, the choice of words and use of vocabulary can be different for each individual depending on their personality traits. In this study, we use Linguistic Inquiry and Word Count (LIWC2015) software to analyze the content of emails from a sample of Enron and Facebook executives. We compare the attributes revealed in these emails at the individual and company level. The results of the analysis indicate that there are significant differences in the personality traits of individuals in the two companies. We show that context analysis can be used as an aid to gain insight on the attributes of business leaders and such tool can potentially aid in identifying the fraud risk among a company's C-suite executives.
\end{abstract}

Keywords: Linguistic analysis; LIWC2015; Enron; Facebook.

*Corresponding Author

\section{INTRODUCTION}

Analysis of written texts and the meta data in those texts can help identify underlying character traits about its author. The linguistic analysis of such texts provides insights into the writer's personality. Such character traits can be evaluated for an individual or for a group of individuals. Analysis of the written communication of a group may be indicative of the organizational culture existing within that group. In this study, we analyze the written communication (emails) of the executives at Enron and Facebook using Linguistic Inquiry and Word Count (LIWC2015) ${ }^{1}$.

\footnotetext{
${ }^{1}$ LIWC (2015) was created at the University of Texas (Pennebaker et al., 2015) and has been widely used in research studies since the 1990s (for example, Robinson, Boyd, and Fetterman 2014; Ritter, Preston and Hernandez 2013; Underwood, et al., 2012; Holtgraves, 2011; and Tumasjan, et al., 2010). LIWC2015 application uses a predefined set of words (LWIC dictionary) composed of almost 6,400 words, word stems, and select emoticons. Each word in the text being analyzed that match with the LWIC dictionary is assigned to a category. One word can fall
} 
At the conclusion of the Enron trial, the Enron emails were released by the Federal Energy Regulatory Commission (FERC) in 2003. The Enron dataset consists of emails sent by more than 150 senior executives. The British parliament released emails of Facebook executives in 2018 as a result of Mark Zuckerberg's refusal to appear before a parliamentary committee. Those emails included two hundred and fifty pages of private Facebook's emails sent between 2012 and 2015.

In this study, we analyze and identify the differences in personality traits of executives at Enron and Facebook by analyzing the wording of their emails. Enron and Facebook serve as proxies for a "fraud-company" and the typical "non-fraud-company", respectively. The emails of selected executives from both companies were collected and analyzed to identify their character traits based on the words used in these emails. The differences in such personality traits has the potential to help identify executives exhibiting a predisposition toward fraudulent behavior.

This paper is organized into six sections. Section two identifies similarities and differences in the background of Enron and Facebook. We discuss prior studies in section three and describe the data collection procedure in section four. Section five provides details and results of analysis. Section six discusses the limitations of the paper and section seven concludes the paper.

\section{COMPARISONS BETWEEN ENRON AND FACEBOOK}

Enron operated in energy sector while Facebook is a technology industry, specifically in social media. Enron's 2000 10-k annual report identifies business operations in transportation and distribution, wholesale services, retail energy services, broadband services, and other as

under multiple categories. For example, the word cried is part of five word categories: sadness, negative emotion, overall affect, verbs, and past focus. 
business segments. The largest source of revenue for Enron was from wholesale services which involved the marketing and delivery of physical commodities and financial and risk management services. Enron's Internet online trading platform resulted in $\$ 2.5$ billion a day in trading volume in 2001. On the other hand, Facebook disclosed in its 2018 10k annual report that it operates as a single entity that generates substantially all its revenue on its Internet platforms from advertising revenues. Though these are obvious differences between the two companies, many commonalities exist. For example, Enron was founded by a charismatic leader, Ken Lay, who led the company into a new and innovative business strategy using an online commodity trading platform. Facebook was founded by Mark Zuckerberg another charismatic leader. Both companies experienced initial tremendous growth in their business operations. Facebook's business model is entirely reliant on the Internet, and so was Enron's online trading platform (Enron Online) where billions of commodities were traded. To expand its online footprint in 2000, Enron was working on a contract agreement with Blockbuster to provide online music, games, and movies which was a streaming breakthrough for that time period. Enron was regarded to be one of the most innovative companies at the time. It received "America's Most Innovative Company" award from Fortune for six consecutive years between 1996 and 2001. Facebook with its new mobile ad formats including full-screen, 360-degree videos, and interactive ads has also been an innovative company that essentially changed the way people interact with each other. Another similarity is that both companies were leaders in their respective businesses. Enron was the number one seller of natural gas in North America, and Facebook is the number one social media company. Consequently, management of both companies need to deal with controversy, strong competition, and threats against their business models. 
Enron and Facebook have both been criticized and there are (were) controversies surrounding the companies. However, a major difference between the two companies is that Enron's executives were found guilty of a financial conspiracy whereas Facebook's executives have never been charged with any financial fraud. At Enron, several executives including CEO Kenneth Lay, CFO Andrew Fastow, and former CEO Jeffrey Skilling were convicted and sentenced for fraud and conspiracy. In this study, Enron and its executives represent a financially fraudulent company. Although a lawsuit was filed against Facebook for alleged privacy violations in 2018, the case has not been settled. ${ }^{2}$ Yet no one is alleging that Facebook and its executives are guilty of financial fraud. Therefore, it is not unreasonable to consider Facebook as representative of a typical "non-fraud" company. In this study, a comparison is made between the personality traits exhibited by executives at Enron and Facebook. These two corporations represent "fraud" and "non-fraud" organizations, respectively, for this study.

\section{PREVIOUS STUDIES OF ENRON'S DATESET}

Prior studies have examined the Enron email dataset to identify various aspects of linguistic characteristics in the emails. Diesner, Frantz, and Carley (2006) used network analysis to investigate the structure, behavior and idiosyncrasies of communication networks in Enron. The authors report that previously disconnected employees engage in mutual communication during a crisis period. The authors also report that messaging interactions bypassed formal chains of communication during the crisis period. Kang, et al (2010) studied the "content-actor" relationships in the emails using NetLens. The analysis identified paired content and individual relationships. Brandy (2015) used the Enron emails to examine the mechanisms that individuals use to remain undetected when sharing information. The authors found that the members of

\footnotetext{
${ }^{2}$ Facebook has set aside \$5B for possible fines related to the Cambridge Analytica Data case.
} 
corrupt projects communicate less and have fewer reciprocal relations than the non-corrupt project members. Network analysis of the emails was used by Fragale, et al. (2012). They used linguistic markers to determine signs of reverence within the content of the emails. Mohammad, (2012) analyzed Enron emails to examine the differences of emotions in mails. The author reports differences among genders in the use of emotional words. Salami (2014) studied the Enron email corpus to investigate the simplicity of email communication. The author found that the readability of emails change with change in the hierarchical direction of communication, hierarchical distance between communicators, and the size of the audience. Past researchers have used the Enron corpus to determine personal network relationships among the executives and staff (Gahrooei, et al. 2018; Fox, et al. 2016; Zan and Lin 2009; McCallum, Wang, and CorrandEmmannel 2007; Kurihara, Kameya, and Sato, 2006;). Other researchers have used a linguistic analysis of email to study employee threat risk and forensic authorship (Brown, Watkins, and Greitzer, 2013; Wright 2014). Previous studies are largely concerned with identifying characteristics of the linguistic networks in the emails and not with identifying the traits associated with fraudulent behavior.

\section{DATA}

For the purpose of this study, private emails sent by executives from Enron and Facebook were analyzed using LIWC2015 linguistic software. Both set of emails were released as a result of legal cases involving the companies. The Enron scandal became public knowledge in October 2001 and Enron's emails were released in $2002 .{ }^{3}$ Facebook emails were released in the UK by a

\footnotetext{
${ }^{3}$ There is no exact date for when the fraudulent activities at Enron actually began. The public became aware of the fraud in October 2001.
} 
parliamentary committee at the end of 2018. Although the Enron emails have been used in prior studies, as noted, the Facebook emails have not been previously used in research of this nature.

The Enron dataset consists of over 500,000 messages sent by 158 Enron executives over a three-and-half-year period from 1999 to 2002. The subpoenaed data was made public by the Federal Energy Regulatory Commission in May 2002. These emails were sent when Enron was in crisis at a time when many at Enron were aware of the company's underlying problems even though they had not become public knowledge. The database includes $92 \%$ of Enron staff emails. $^{4}$ None of the emails included attachments. The Enron executives' emails in the dataset were sent by senior managers thirty-five of whom were indicted and charged with fraud and conspiracy for their involvement in the fraud. In this study, we analyze the emails of the top six Enron executives. They are: (1) Kenneth Lay, founder of Enron; (2) Jeffrey Skilling, CEO; (3) Andrew Fastow, CFO; (4) Kenneth Rice, CEO of broadband services; (5) Mark Koenig Head of Investor Relations; and (6) Ben Glisan, Treasurer. We chose these executives because of their significant role and responsibilities in determining Enron's financial results.

Before analyzing the Enron emails, the dataset was converted into a corpus ${ }^{5}$ for analysis. Previous studies have also developed an Enron corpus for analysis by eliminating extraneous data in the emails. The email headers and duplicate emails were manually removed before analysis.

\footnotetext{
${ }^{4}$ See: Information Released in the Enron Investigation https://www.ferc.gov.

${ }^{5} \mathrm{~A}$ dataset is the raw data that is collected. A corpus is the dataset that has been cleaned up. As in the case of emails, headers and dates have been manually removed and typos corrected. We corrected typos to understand the intended communication in the email. We also suspect that some typos may have been created during the digital transformation of the emails from one source to other. We took this additional step to remove typos, but LIWC2015 converts all text files to lower case before processing them therefore grammar, capitalization, and sentence structure are not required to be corrected. Finally, it should be noted that an annotated corpus is created from the corpus by grammatically separating the words in the corpus into different categories such as positive or negative connotations.
} 
The Facebook emails are available in several online sources (for example:

https://www.parliament.uk/documents/commons-committees/culture-media-and-sport/Note-byChair-and-selected-documents-ordered-from-Six4Three.pdf). Two-hundred and fifty pages of private Facebook's emails, sent between 2012 and 2015, were released by the U.K Parliament. Originally, they were collected as evidence in a California lawsuit against Facebook by Six4Three an app development company (Roose 2018). Six4Three alleged that Facebook was restricting their access to user data on the Facebook platform. The U.K.s Digital, Culture Media, and Sports Committee seized these documents as part of a larger investigation into Facebook's practices in the U.K. Eventually the emails were put online in 2018. The Committee had been investigating Facebook's role with Cambridge Analytica (CA). CA had harvested private information from the Facebook platform and used it for political purposes. Facebook's emails were released because Mark Zuckerberg would not testify before the Parliamentary committee reviewing Facebook's practices.

Executives and staff emails were included in the release. The following top executives' emails in the exchanges were chosen for analysis: (1) Mark Zuckerberg, CEO; (2) Konstantinos Papamiltidas, Director of Platform Partnerships; (3) Sam Lessin, VP of Product Development Related to Partnerships; (4) Simon Cross Product Manager, Plugin Apps; and (5) Sachin Monga, Platform Team, Social Media Interactions. ${ }^{6}$ These executives were chosen as they were the highest-ranking executives involved in the email exchanges. Although these executives did not have the same job functions as those executives at Enron, their decision-making oversight in the organizational hierarchy matched those of the executives in Enron. As with the Enron dataset,

\footnotetext{
${ }^{6}$ The emails were collected from a discussion thread used by the top executives at Facebook to discuss their platform business practices.
} 
we cleaned up the Facebook emails by removing headers and other peripheral elements and only the text of the emails were included in the analysis.

\section{ANALYSIS}

The context analysis was used to study the Enron and Facebook corpus. ${ }^{7}$ Context analysis categorizes large amounts of textual material or corpus to identify word patterns that lead to the identification of the writer's personality traits (Pollach 2012; Pennebaker 2011; Pennebaker et al., 2003; Cohn et al., 2004; McCrae and Costa 1996). Once the word patterns are categorized based on lexical categorizations used by a mapping tool for automated context analysis, an annotated corpus is created. LIWC2015's categorizations were used for that purpose. The tool maps a text file with counts on dictionary determined categories as well as the different senses that can be assigned or tagged to a word, such as sadness or anxiety, based on an algorithm. ${ }^{8}$ The algorithms in the tool have been independently rated by linguists and tested for reliability (Tausczik and Pennebaker 2009). Li and Chignell (2010) followed this approach to show how personality types could be identified with the words written by blog writers. Argamon et al., (2005) and Oberland and Gill (2006) also used this approach and found word usage could identify the trait of extroversion in writers. Pennebaker (1999, 2002, 2003, and 2011) has written extensively about the relationship between the personality traits associated with writing style. Pennebaker and King (1999) state:

Thus, language use may be thought of as an arena in which the impact of the person is unavoidable (p. 1309).

\footnotetext{
${ }^{7}$ There is a difference between the meaning of "content" and "context." In linguistic applications, content is what is written whereas context is concerned with the meta data structure behind the written text.

${ }^{8}$ In an annotated corpus that is grammatically tagged, words have been assigned word labels. Examples of categorization tools that can be used to develop an annotated corpus are the General Inquirer, Diction 7.0, KH Coder, Minnesota Contextual Context Analysis, and Whissell's Dictionary of Affect in Language. Some of these are freely available online. Several of these tools are only provide limited results and others have not been maintained such as the General Inquirer. Although the algorithm used among tools may differ, the results from the LIWC2015 have been widely used and tested in research studies. For that reason, the LIWC 2015 was chosen over other categorization tools.
} 
Other authors have adapted this methodology with business datasets. Demers and Vega (2010) used this methodology to evaluate earnings reports. Abrahamson and Park (1994) used context analysis to identify traits found in the letters sent to stockholders. Smith (2017) used this methodology to identify characteristics of accountants in literature. Ingram and Frazier (1983) used context analysis to investigate environmental disclosures from a sample of firms. ${ }^{9}$

\section{The Background for the Analysis.}

There are many well-recognized categorization tools for context classification. Within these categorization tools, there are word dictionaries with meanings assigned to word usages. One such system, in use since the 1990s, is the linguistic tool LIWC2015. LIWC2015 was developed by coders with linguistic backgrounds (Pennebaker, et al., 2015). LIWC2015 has been widely used to identify traits in various documents from texts to tweets (Robinson, Boyd, and Fetterman 2014; Ritter, Preston and Hernandez 2013; Underwood, et al., 2012; Holtgraves, 2011; and Tumasjan, et al., 2010).

LIWC2015 allows for the linguistic patterning of text to identify traits associated with a writer. It is composed of two basic parts: (1) dictionaries and (2) algorithms to process text. Essentially, LIWC2015 collects meta data from within a text. The LIWC2015 dictionary contains nearly 6,400 words, word stems, and emoticons used to process text. LIWC2015 captures eighty-six percent of the words people use in writing and speech (Pennebaker, et al.,). Independent judges were initially used to build word lists in the dictionaries. Later, other groups of judges continued to rate the goodness of fit for the 81 categories in LIWC2015 as well as the

\footnotetext{
${ }^{9} \mathrm{~A}$ limitation of context analysis is that it is difficult to establish a causal relationship to the word categories. In our paper, although suggestions are made as to the reason for aggregated trends in scores, we are not attempting to identify a specific cause of these traits.
} 
words in the dictionary. In LIWC2015, the most recent version, summary variables were added to the categories. These variables are: (1) analytical thinking; (2) clout; (3) authenticity; and (4) emotional tone. These variables are the only non-transparent section of the ratings as shown in Table 1. Although words are grouped into these four categories, no word examples are disclosed in LIWC2015 due to commercial development agreements. Before being released, the LIWC2015 was tested by measuring each category for reliability and validity scores based on real-world text sets (Pennebaker, et al., 2015).

LIWC2015 process text files sequentially. It finds each word and then determines if it is in its dictionary. Next, it includes that word in its count, and uses those word totals to calculate a percentage function, i.e., as a percentage of the total words in the document. Words not counted are not part of the total word count. It then uses a scaled algorithm to determine a psycholinguistic category as its output. Word counts and word percentages are summed by category. Before counts are made, the word roots are lemmatized by reducing word stems by removing suffixes such as "ly" "ion" or "ing" or "ize" and "izes." It should also be noted that one word may fit in several category traits. In those cases, the word might contribute to such characteristics as both "sadness" and "negative emotion".

\section{The Sample.}

The analysis of the dataset begins with a selection of the trait categories. The selection was based on those traits that would be most revealing regarding possible fraudulent behavior. For example, the power and overconfidence associated with narcissistic behavior was considered to be important for the analysis. Each email was checked for correct spellings, typos ${ }^{10}$ and

\footnotetext{
${ }^{10}$ We correct typos before running analysis because LIWC2015 will drop words that are not in dictionary and would not count these words in the analysis. Keeping typos would drop those words from the analysis and make the results less reliable.
} 
converted into the proper file format before being processed with the LIWC 2015. The emails from Enron and Facebook were processed using the nineteen traits in Table 1. The main divisions in Table 1 are Linguistic and Psychological Processes. Linguistic Processes identified by LIWC2015 are language descriptions such as counts of verbs, nouns, adverbs, and prepositions for example. These are described as "function words." From a linguistic viewpoint, functional words show how people view and interact with the world around them. Table 1 lists the Summary Variables for Linguistic Processes under this category as well as those for Numbers and Negations such as "no." Psychological Processes and their subclassifications are used to identify the emotional context in the email samples.

\section{[INSERT TABLE 1 HERE]}

\section{Enron and Facebook Traits.}

We first analyze the emails of Enron executives. To get the LIWC score for individual executives, we merge all emails of each Enron executive into one text document for each executive and then analyze the texts using LIWC2015. Results of the analysis are presented in Table 2.

\section{[INSERT TABLE 2 HERE]}

Table 2 presents the LIWC2015 score of nineteen traits for the Enron executives selected for the analysis. The word counts (WC) represents the total number of words analyzed by LIWC2015. As expected Kenneth Lay and Jeffery Skilling have the highest number of words in the analysis as they are the Founder and CEO and CEO of the companies respectively. Many communications in a company comes from the CEO to the employees on regular basis. Next, the table presents the scores of the executives on various attributes. We highlight the largest scores 
in each trait by blue and the lowest score by red. The scores represent the percentage of the words in each category used by each of the executives. For example, Jeffery Skilling has the largest analytic score (91.66) and Andy Fastow has the lowest analytic score (52.35). This means that $91.66 \%$ of the words used by Jeffery Skilling are categorized as analytical while $52.3 \%$ of the words used by Jeffery Skilling are categorized as analytical. It should be noted that there is no benchmark (or norm) for scores in each category for a normal person. The difference in the scores can be interpreted as Jeffery Skilling uses more analytical language than Andy Fastow. However, we cannot conclude that Andy Fastow is a person with low analytic skill.

As the comparative results in Table 2 are reviewed, the highest and lowest percentage scores in each row are highlighted as blue or red, respectively. The first trend that becomes apparent are the scores for Andrew Fastow, Enron's CFO. Mr. Fastow shows the highest scores for Negate (inhibition), Negative emotions (Negemo), Anger, Sadness, Tentativeness, and Focus on the present (Focuspresent). His lowest scores are for Analytic, Clout, Tone, and positive emotions (Posemo). His psychological traits display less self-assurance, and more neurotic issues such as Anger. He is not confident about his leadership (Clout), has more anxiety and hostility (Tone), and faces more inhibition than the other executives. The causality these personality traits cannot be identified, yet it serves as a marker of concern for the CFO of one of America's largest corporations to exhibit such traits. As CFO, he was dealing with the financial issues facing Enron daily and knew how close the company was to fiscal collapse.

In Table 2, Ken Lay's traits show high levels of Clout, Power, as would be expected, and a focus more on the future and less on the present than the other executives. Most of the executives were not very concerned with any threat issues such as Anxiety or Anger ( 0.0 scores) which is an indication of their high level of confidence in themselves. The most notable trait 
exhibited by Jeffrey Skilling was his Analytical approach to problems, which is a measure of intelligence. He also had a very low (.39) score for the Negate trait which is a measure of inhibitions such as shyness. Other traits such as Sad and Negemo exhibited the same tendencies. He had few worries about Risk which indicates there is little room for doubt in his life.

We also analyze the emails of Facebook executives. To get the LIWC score for individual executives, we merge all emails of each Facebook executives into one text document for each executive and then analyze the text using LIWC2015. Results of the analysis are presented in Table 3. The comparative results for the five Facebook executives shown in Table 3 are for the same set of traits as in Table 2. The Facebook executives in Table 3 were involved with product development. This product development was directed at settling how Facebook was going to allow app developers and media companies, such as Netflix, to interact and have access to the Facebook platform. This development group was responsible for setting policies as to pricing and full or limited access to Facebook's data. The email exchanges are an extensive collection of their views about these issues.

\section{[INSERT TABLE 3 HERE]}

In reviewing the results of Table 3, it can be seen that Mark Zuckerberg, CEO of Facebook, exhibited strong traits of Authenticity, Risk, and Money as compared with the other executives. High authenticity reflects honesty as noted in Table 1. Yet, his concern with risk and financial issues likely affect his other personality traits. This is apparent as he has the highest scores in Negate, Negmo, and Tentat compared with the other executives. Inhibition, negativity, hesitation in decision making are part of these traits (as seen in Table 1). Such traits tend toward hesitation in decision making. These are personality traits that are not exhibited by 
Lay or Skilling at Enron. Lay's and Skilling's email messages exhibited Power and Clout as seen in Table 2.

Two employees at Enron and Facebook had job functions that were directly related to product management. At Enron, Kenneth Rice was CEO of broadband services, a separate product, and at Facebook, Simon Cross was a product manager dealing with apps allowed on its platform. When the traits of these two executives are compared, there are marked differences. Rice's traits exhibit positive emotions (Tone 98.35; Posemo 5.79; and Insight 3.28). When Simon Cross' traits compared (Tone 55.66; Posemo 2.45; and Insight 0.86), there are strong negative scores. Although there are differences in the job functions among product managers, they are generally responsible for the success or failure of a product line. Simon Cross further demonstrates a fundamental difference in traits between Facebook's and Enron's C-suite. Most of the executives at Enron, except for Andy Fastow, seemed exhibited a strong sense of selfassurance in themselves as found in Jeffrey Skilling's traits.

Several authors have identified a correlation between narcissistic behavior and fraudulent tendencies (Johnson, et al. 2013; Rijsenbilt and Commandeur 2013; Cohen et al. 2010; Blickle et al. 2006). Characteristics of narcissism include the need for power, dominance and an unrealistic belief in themselves. Narcissistic personalities tend to use manipulation and risky behavior to achieve their goals. Skilling has been described as an executive who developed "a charisma aura around him (self)." He singularly promoted himself and his views (Essays 2018). He had the power to gain the loyalty of employees through rewards and granting status.

Schrand and Zechman (2009) and Chen (2010) also found a correlation between fraudulent behavior and overconfidence. Corporate leaders usually have a high level of confidence in themselves. Yet, Skilling was overly confident in his abilities with the initial 
success of Enron and his recognition in the nation as an icon of a successful business leader.

Personality traits such as concerns with power, domination, and displays of overconfidence are correlated with fraudulent behaviors. In Table 3, Jeffrey Skilling (3.83) and Ken Lay (3.88) both exhibit traits associated with Power as compared with the other executives at Enron and Facebook's Mark Zuckerberg (1.47). The traits at Enron's were defined by dominance and overriding confidence.

Table 4 presents comparison of the traits for the CEOs of Enron and Facebook. For the purpose of this comparison, we analyze each email of the executives separately. Then we compute the average score of the traits for the executives. We then perform t-test to examine whether the average score of the executives are significantly different ${ }^{11}$. We highlight the attributes that are significantly different (having p-value less than 0.05) in red.

\section{[INSERT TABLE 4 HERE]}

As seen in table 4, there are significant differences in the attributes of the two executives such as Analytic, Negate, Posemo, Tentat, Power, and Focuspresent. Zuckerberg exhibited more uncertainty (Negate, Tentat) in his messaging than Skilling. Skilling showed more of a power orientation in his messages. A strong Power trait indicates that Skilling, as CEO, used a management style that exercised higher levels of direct control over his subordinates. When an executive uses a high level of control, he is confident in his decisions, a trait Skilling exhibited. This difference in traits between Skilling and Zuckerberg is particularly apparent in the scores for Tentat. A higher percent of the words used by Zuckerberg (4.94) are associated with tentativeness. Thus, Zuckerberg may be more open in making decisions. He is less controlling

\footnotetext{
${ }^{11}$ To make the comparison, each executives' score on each email message was separately averaged for the nineteen characteristics. For example, all emails of Zuckerberg are analyzed separately to get the score for each attributes. Then we compute the average score of each attribute for Zuckerberg. We do the same for Skilling and perform ttest to compare the average score. This approach is used for the results presented in Tables 5, 6, 7, and 8.
} 
and thus more open to the views of his executive group. Skilling is not tentative in his messaging (1.29). Although the percentage scores show there is not much of a comparative difference between the two executives in future focus, there is a significant difference in their focus on the present. Zuckerberg is much more focused on the present than Skilling who may have other executive interests.

Table 5 presents the comparison of the traits depicted in the emails of Enron and Facebook executives. The average score presented in the table is computed by separately analyzing each email of the executives in the respective companies. After that we compute the average score in each trait based on the scores for each emails. Traits that are significantly different (p-value less than 0.05) are shown in red.

\section{[INSERT TABLE 5 HERE]}

As seen in Table 5, there is significant difference in the Negemo, Sadness, Tentat, Power, Risk, and Money traits between Enroon and Facebook emails. Taken together, it paints a picture of Enron's executives as being more neurotic, power/dominant and risk orientated, along with having a direct concern about themselves. Facebook executives exhibit significantly less of these traits as compared with Enron. In addition, Facebook executives exhibit a lower level of self-assurance in their messaging compared with the high level of confidence found in Enron's emails. The executives who were involved in the Enron fraud appear to be very sure of themselves, concerned with their own interests, confident in their opinions, and they exercised a power or control style not found in use at Facebook The combination and interaction of these traits led to the fraudulent financial scheme that defrauded investors. After the extent of fraud 
was revealed, an example of Skilling's completed confidence in himself led to his 2002 unrestrained testimony in front of Congress. ${ }^{12}$

The Enron Executives. So far, our discussion and analysis has focused on the differences between Enron and Facebook executives. We next look at the potential of differences between the Enron executives. In this section, we compare and identify differences in the traits of Fastow and Lay and Fastow and Skilling. This comparison has been presented in tables 6 and 7 respectively. These executives were most involved in the fraud as well as most responsible for formulating Enron's strategic plans, so it is worthwhile to compare their trait patterns.

Fastow's traits have so far shown a stronger negative orientation. As CFO, he was involved in keeping losses off Enron's books. Therefore, comparing his attributes with the other two executives has the potential to reveal some differences in their personality traits. As seen in tables 6 and 7, Lay and Skilling have more clout than Fastow. Therefore, we can expect that the power in the relationship to be on the side of Lay and Skilling. One trait that a CFO should possess is "Authentic" which measures honesty and full disclosure in messaging and relationships. Consistent with this expectation, Fastow shows a significant difference on this trait with Lay (p-value 0.0263) and a higher orientation toward this trait compared to Skillling but not statistically significant.

[INSERT TABLE 6 HERE]

[INSERT TABLE 7 HERE]

\footnotetext{
${ }^{12}$ Skilling is the only member of Enron's senior management to testify before Congress, appearing before a House subcommittee earlier this month. April Witt. February 27, 2002. Skilling's Testimony Met With Skepticism. The Washington Post. Accessed April 8, 2019. https://www.washingtonpost.com/archive/politics/2002/02/27/skillingstestimony-met-with-skepticism/b65cc993-4017-4735-a49c$\underline{012 \mathrm{e} 027 \mathrm{e} 61 \mathrm{~d} 2 / \text { ?noredirect }=\text { on\&utm_term }=. \text { be } 783 \mathrm{f} 4 \mathrm{~d} 6694}$
} 
A closer look at tables 6 and 7 indicate that Fastow has more negative traits than either Lay or Skilling. He has less Clout than Skilling and Lay. Fastow has exhibited little selfassurance along with many inhibitions (Table 2). As CFO, he appears to have a compliant role to the other two executives. There are indications that when a relationship such as this one exists between a group of the executives; the less powerful executive is strongly under the influence of the more powerful executives. It appears that both Lay and Skilling had control and power over Fastow.

\section{LIMITATIONS OF THE STUDY}

One weakness of context analysis is that positive words are used in phrases that might have negative connotations. For example, the word "cool" as related to a person might have the meaning that a person is "really hip" or that they are standoffish. Research related to determining the connotation of a word based on the phrase in which the word appears is still under development (Wilson et al., 2009). The corpus used in LIWC2015 attempts to overcome this problem by considering the phrase not just the word in isolation. Another limitation of context analysis is coding bias due to the subjectivity among the various linguists performing the coding. LIWC2015 has been consistently used for coding traits since the 1990s, and it is a widely recognized research tool used for context analysis. Therefore, coding bias is not considered an issue.

Finally, another characteristic of context analysis that influences its use is that it does not provide for causality of the results. Therefore, a cause cannot be associated with a trait. There is no speculation provided as to the causality of the traits identified in the datasets.

\section{CONCLUSION}


It has been shown that there are important traits associated with Skilling and Zuckerberg, especially, that are significantly different. As leaders of the companies, they exhibit personal traits that steered the companies in different directions. Skilling's traits reflect those of someone who was highly motivated by Power who had high levels of confidence in his actions and wanted control over his employees. Although confidence is important for a leader of a company, overconfidence can lead to myopic decisions made without consultation. The traits associated with Skilling are those of a narcissistic personality and may be linked with fraudulent behavior. Zuckerberg appears to be a leader who is interested in consultative relationships. The traits identified in his emails show that is he hesitant in making decisions with consultation, and his management style is more participative than those executives who controlled Enron.

It is also apparent that Andy Fastow did not have the Power or Clout to change the operational strategies toward which Enron was being directed. Lay's and Skilling's Power and Clout trait levels were much stronger than Fastow's. This disparity may have implications as to the source of the fraudulent activities at Enron.

Future researchers should consider the application other linguistic tools for evaluating fraudulent traits in other organizations with the purpose of developing a more extensive dataset and list of "fraudulent" traits. The results in the paper indicate that the "red flag" traits of fraud, such as narcissism, exist and can be identified using LIWC2015. If there is a suspicion of corporate fraud within an organization, one of the tools that may be used to solidify that assumption is context analysis. Context analysis can be used as a preemptive tool by forensic fraud investigators. It will not identify the fraud, but through the analysis of C-suite writing samples, it can determine if concerns about potential fraud within an organization should be amplified. Context analysis is a tool for forensic profiling. 
Context analysis can be used to identify traits in numerous documents. Some studies based on financial reports have been described in the paper. Yet, there are other areas for such analysis. For example, editorials in accounting journals, corporate conference calls, review notes, and reports in the financial press can provide a rich source of information about underlying attributes of the writer. Such an analysis can help to identify biases of the writer that may not be initially apparent.

\section{References}

Abrahamson, E. and C. Park (1994). Concealment of negative organizational outcomes: an agency theory perspective. Academy of Management Journal 37(5): 1302-1334.

Argamon, S. and L. Shlomo (2005). Measuring the usefulness of function words for authorship attribution. In Proceedings of ACH/ALLC Conference, University of Victoria, BC, Association for Computing and the Humanities, 1-3.

Aven, B. L., (2015). The paradox of corrupt networks: An analysis of organizational crime at Enron. Organization Science 26 (4): 980-996 
Blickle, G., P. Schlegel, and U. Klien (2006). Some personality correlates of business whitecollar crime. Applied Psychology: An International Review 55(2): 220-233.

Brown, C., A. Watkins, and F. Breitzer (2013). Predicting Insider Threat Risks through Linguistic Analysis of Electronic Communication. In 2013 Hawaii International Conference on System Sciences. 1849-1858.

Cameron, K. and R. Quinn (2006). Diagnosing and Changing Organization Culture. JosseyBass: San Francisco, CA.

Chen, S. (2010). The role of ethical leadership versus institutional constraints: A simulation study of financial misreporting by CEOs. Journal of Business Ethics, 93, 33-52.

Cohn, A., M. Mehl, and J. Pennebaker (2004). Linguistic markers of psychological change surrounding. Psychological Science 15(10), 687-693.

Demers, E. and C. Vega (2010). Soft information in earnings announcements: news or noise?", Unpublished paper, SSRN eLibrary, available at: http://ssn.com/paper_1152326

Diesner, J., T. Frantz, and K. Carley (2005). Communication networks from the Enron email corpus "It's always about the people. Enron is no Different." Computational \& Mathematical Organization Theory, 11, 201-225.

Enron email dataset, http://www.cs.cmu.edu/ enron. Accessed February 5, 2019.

Essays, (2018). Organizational Culture and Leadership Styles of Enron. Retrieved: April 2019. https://www.ukessays.com/essays/management/the-organizational-culture-andleadership-styles-of-enron-management-essay.php?vref=1

Facebook email dataset, https://www.parliament.uk/documents/commons-committees/culturemedia-and-sport/Note-by-Chair-and-selected-documents-ordered-from-Six4Three.pdf. Retrieved: February 16, 2019.

Fragale, A., Alison, R., Sumanth, J. Tiedens, L., and Northcraft, G. (2012). Appeasing equals: Lateral deference in organization communication. Administrative Science Quarterly, 57(3) 373-406.

Fox, E., Short, M., Schoenberg, F., Coronges, K. and Bertozzi, A. (2016). Modeling e-mail networks and inferring leadership using self-exciting point processes. Journal of the American Statistical Association 111(514) 564-584.

Gahrooei, M., and Paynabar, K. (2018). Changed detection in a dynamic stream of attributed networks. Journal of Quality Technology, 50(4) 418-430. 
Gibert, D. (2018). Here's what's in the 250 pages of secret emails the UK just released. Vice. Retrieved: April 4, 2019. https://news.vice.com/en_us/article/439qeb/heres-whats-in-the250-pages-of-secret-facebook-emails-the-uk-just-released.

Hales, S. and G. Rabey (2011) The frontline manager: fronting up to organizational change. Industrial and Commercial Training, (43)6, 368-376.

Holtgraves, T. (2011). Text messaging, personality, and the social context. Journal of Research in Personality, 45, 92-99.

Huang, Z. and Lin, D. 2009. The time-series link perdiction problem with applications in communication surveillance. INFORMS Journal on Computing 21(2) 286-303.

Ingram, R., and K. Frazier (1983). Narrative disclosures in annual reports. Journal of Business Research, 11, 49-60.

Johnson, E., J. Kuhn, B. Apostolou, and J. Hassell (2013). Auditor perceptions of client narcissism as a fraud attitude risk. Auditing: A Journal of Practice \& Theory, 32(1), 203219.

Kacewicz, E., J. Pennebaker, M. Davis, M. Jeon, and A. Graesser (2013). Pronoun use reflects standings in social hierarchies. Journal of Language and Social Psychology, 33, 125143.

Kang, H., Plaisant, C., Elsayed, T., and Oard, D. (2010). Making sense of archived e-mail: Exploring the Enron collection with NetLens. Journal of the American Society for Information Science \& Technology, 61(4), 723-744.

Kurihara, K., Y. Kameya, and T. Sato (2006). A frequency-based stochastic blockmodel. In Workshop on Information Based Induction Sciences.

Li, J. and M. Chignell (2010). Birds of a feather: How personality influences blog writing and reading. International Journal of Human-Computer Studies 68(9), 589-602.

McCallum, A., X. Wang, and A. Corrada-Emmanuel (2007). Topic and role discovery in social networks with experiments on Enron and academic email. Journal of Artificial Intelligence Research, 30, 249-272.

McCrae, R. and P. Costa (1996). Toward a new generation of personality theories: Theoretical contexts for the five-factor model. In Jerry S. Wiggins (ed.) The Five-Factor Model of Personality: Theoretical Perspectives. Guilford: New York, 51-87.

Mohammad, S. M., (2012). From once upon a time to happily ever after: Tracking emotions in mail and books. Decision Support Systems 53(4): 730-741.

Newman, M., J. Pennebaker, D. Berry, and J. Richards (2003). Lying words: Predicting deception from linguistic styles. Personality and Psychology Bulletin 29, 665-675. 
Oberlander, J. and A. Gill. (2006). Language with Character: A stratified corpus comparison of individual differences in e-mail communication. Discourse Processes, 42(3), 239-270.

Orio, P. (2018). Three skills that hospital administrators should possess-availability, affability and ability. Journal of Hospital Management and Health Policy. Retrieved: March 30, 2019. http://jhmhp.amegroups.com/article/view/4114.

Pennebaker, J., R. Boyd, K. Jordan, and K. Blackburn (2015). The development and psychometric properties of LIWC201. Austin, TX: University of Texas at Austin.

Pennebaker, J., C. Chung, J. Frazee, G. Lavergne, and D. Beaver (2014). When small words foretell academic success: The case of college admissions essays. PloSOne, 9, 1-10.

Pennebaker, J. (2011). The secret life of pronouns: What our words say about us (Bloomsbury Press, New York).

Pennebaker, J., M. Mehl, and K. Niederhoffer (2003). Psychological aspects of natural language use: Our words, our selves. Annual Review of Psychology 54, 547-577.

Pennebaker, J. and L. King (1999). Linguistic styles: Language use as an individual difference. Journal of Personality and Social Psychology, 77(6) 1296-1312.

Pollach, I. (2012). Taming textual data: the contribution of corpus linguistics to computer-aided text analysis. Organizational Research Methods 15(2), 263-287.

Rijsenbilt, A. and Commandeur, H. (2013). Narcissus enters the courtroom: CEO narcissism and fraud. Journal of Business Ethics 117(2), 413-429.

Ritter, R., J. Preston, and I. Hernandez (2013). Happy tweets: Christian are happier, more socially connected, and less analytical than atheists on twitter. Social Psychology and Personality Science. Retrieved: March 9, 2019. http://spp.sagepub.com/context/early/2013/06/18/1948550613492345

Robinson, M., R. Boyd, and A. Fetterman (2014). An emotional signature of political ideology: Evidence from two linguistic context-coding studies. Personality and Individual Differences 71 , 98-102.

Roose, K. (2018). Facebook emails show its real mission: Making money and crushing competition. New York Times, December 6 (Section B).

Schrand, C. and S. Zechman (2009). Executive overconfidence and the slippery slope to fraud. SSRN elibrary. Retrieved: April 5, 2019. https://papers.ssrn.com/sol3/papers.cfm?abstract_id=1265631 
Smith, A., D. Plowman, D. Duchon, and A. Quinn (2009). A qualitative study of high-reputation plant managers: Political skill and successful outcomes. Journal of Operations Management 27(6), 428-443.

Smith, G. (2017). The accountant: A character in literature. Meditari Accountancy Research 25(1), 2-27.

Tausczik, Y. and J. Pennebaker (2009). The psychological meaning of words: LIWC and computerized text analysis methods. Journal of Language and Social Psychology 29(1), 24-54.

Tumasjan, A., T. Sprenger, P. Sandner, and I. Welpe (2010). Predicting elections with Twitter: What 140 charqacters reveal about political sentiment. Fourth International AAAI Conference on Weblogs and Social Media.

Underwood, M., L. Rosen, D. More, S. Ehrenreich, and G. Gentsch, (2012). The blackberry project: Capturing the context of adolescents' text messaging. Developmental Psychology. Retrieved: March 9, 2019. https://www.ncbi.nlm.nih.gov/pmc/articles/PMC3289770/

Wilson, T., J. Wiebe, and P. Hoffman, (2009). Recognizing contextual polarity: an exploration of features for phrase-level sentimental analysis. Computational Linguistics 35(3): 399433.

Wimbush, J., J. Shepard, and S. Markham (1997). An empirical examination of the relationship between ethical climate and ethical behavior from multiple levels of analyses. Journal of Business Ethics. 16(16), 1705-1716.

Wright, D. (2014). Dissertation. Stylistics versus Statistics: A corpus linguistic approach to combining techniques in forensic authorship analysis using Enron emails. University of Leeds.

Table 1. The LIWC Traits Selected for the Context Analysis of the Enron and Facebook Datasets

\begin{tabular}{|l|l|l|}
\hline Traits & Description & $\begin{array}{l}\text { Word Examples (total number } \\
\text { of words in category) }\end{array}$ \\
\hline $\begin{array}{l}\text { Part I: Linguistic } \\
\text { Processes }\end{array}$ & & \\
\hline
\end{tabular}

\footnotetext{
${ }^{13}$ Linguistic processes are related to the grammatical characteristics of sentence structure. First person and nonfirst-person descriptions. Counts of verbs, adverbs, prepositions, and pronouns would be a measure of linguistic processes. In Table 1, only the summary variables of these traits are noted along with number and negate word
} 


\begin{tabular}{|c|c|c|}
\hline $\begin{array}{l}\text { Analytic Thinking (see } \\
\text { Pennebaker et al., 2014) }\end{array}$ & $\begin{array}{l}\text { High score: formal, logical, } \\
\text { hierarchical thinking; Low score; } \\
\text { informal, personal, narrative } \\
\text { thinking }\end{array}$ & $\begin{array}{l}\text { Summary Variable: No words } \\
\text { listed }\end{array}$ \\
\hline $\begin{array}{l}\text { Clout (See Kacewicz et } \\
\text { al., 2013) }\end{array}$ & $\begin{array}{l}\text { High score: "high expertise" and } \\
\text { confident; Low score: more } \\
\text { tentative or humble; the score can } \\
\text { indicate confidence and level of } \\
\text { leadership. }\end{array}$ & $\begin{array}{l}\text { Summary Variable: No words } \\
\text { listed }\end{array}$ \\
\hline $\begin{array}{l}\text { Authentic (See } \\
\text { Newman et al., 2003) }\end{array}$ & $\begin{array}{l}\text { High score: honest, personal and } \\
\text { disclosing text; Low score: more } \\
\text { guarded and distanced in } \\
\text { disclosure }\end{array}$ & $\begin{array}{l}\text { Summary Variable: No words } \\
\text { listed }\end{array}$ \\
\hline $\begin{array}{l}\text { Tone (Emotional tone) } \\
\text { (See: Cohn et al., 2004) }\end{array}$ & $\begin{array}{l}\text { High score }(>50) \text { positive or } \\
\text { upbeat emotion; Low score }(<50) \\
\text { more anxiety, sadness, and } \\
\text { hostility. A score of around } 50 \\
\text { indicates ambivalence. }\end{array}$ & $\begin{array}{l}\text { Summary Variables: No words } \\
\text { listed }\end{array}$ \\
\hline Negate (negations) & More inhibition & No, not, never (62) \\
\hline Numbers & $\begin{array}{l}\text { Numerical orientation of the } \\
\text { document }\end{array}$ & Second, thousand (36) \\
\hline \multicolumn{3}{|l|}{$\begin{array}{l}\text { Part II: Psychological } \\
\text { (Emotional) } \\
\text { Processes }^{14}\end{array}$} \\
\hline \multicolumn{3}{|l|}{ Cognitive Processes } \\
\hline $\begin{array}{l}\text { Posemo (Positive } \\
\text { Emotion) }\end{array}$ & More Optimistic; More extravert & Love, nice, sweet (620) \\
\hline $\begin{array}{l}\text { Negemo (Negative } \\
\text { Emotion) }\end{array}$ & More neurotic & Hurt, ugly, nasty (744) \\
\hline Anx (Anxiety) & More neurotic & Worried, fearful (116) \\
\hline Anger & More neurotic & Hate, kill, annoyed (230) \\
\hline Sadness & More neurotic & Crying, grief, sad (136) \\
\hline Insight & Suggest learning or understanding & Think, know (259) \\
\hline Tentat (Tentative) & Less self-assurance & Maybe, perhaps (178) \\
\hline \multicolumn{3}{|l|}{ Drivers and Needs } \\
\hline Power & More control & Superior, bully (518) \\
\hline Reward & Compensation & Take, prize, benefit (120) \\
\hline Risk & Hazard or threat & Danger, doubt (103) \\
\hline Time Orientation & & \\
\hline
\end{tabular}

counts. No word examples are provided for summary variables as required under the contract agreement for developing this section of LIWC2015.

${ }^{14}$ Tausczik and Pennebaker (2010) state "emotion words people use provide important psychological cues to their thought processes, emotional states, intentions, and motivations" (p.37). Table 1 uses a list of emotional traits identified by Pennebaker and associates as pertinent in the context analysis of data. 


\begin{tabular}{|c|c|c|}
\hline $\begin{array}{c}\text { Focuspresent (Present } \\
\text { focus) }\end{array}$ & Current focus & Today, is, now (424) \\
\hline $\begin{array}{c}\text { Focusfuture (Future } \\
\text { focus }\end{array}$ & More goal oriented & May, will, soon (97) \\
\hline Personal Concerns & & \\
\hline Money & More personal oriented & Audit, cash, owe (226) \\
\hline
\end{tabular}

Table 2. LIWC Traits and their LIWC percentage scores for the top six Enron executives convicted in the Enron trial. In the table, the highest score in each row is highlight in blue and the lowest in red.*

\begin{tabular}{|c|c|c|c|c|c|c|}
\hline Executive & $\begin{array}{c}\text { Andy } \\
\text { Fastow } \\
\text { CFO }\end{array}$ & $\begin{array}{c}\text { Ben } \\
\text { Glisan, } \\
\text { Treasure }\end{array}$ & $\begin{array}{l}\text { Kenneth } \\
\text { Lay, } \\
\text { Founder }\end{array}$ & \begin{tabular}{|c} 
Mark \\
Koenig, \\
Investor \\
Relations
\end{tabular} & $\begin{array}{l}\text { Kenneth } \\
\text { Rice, CEO } \\
\text { Broadband }\end{array}$ & $\begin{array}{l}\text { Jeffery } \\
\text { Skilling } \\
\text { CEO }\end{array}$ \\
\hline
\end{tabular}




\begin{tabular}{|c|c|c|c|c|c|c|} 
WC & 467 & 433 & 10502 & 736 & 518 & 2582 \\
\hline Analytic & 52.35 & 90.84 & 84.16 & 78.18 & 60.62 & 91.66 \\
\hline Clout & 41.53 & 69.43 & 89.20 & 70.20 & 74.43 & 87.97 \\
\hline Authentic & 32.06 & 8.34 & 24.02 & 32.09 & 28.36 & 29.32 \\
\hline Tone & 29.35 & 98.25 & 82.28 & 81.93 & 98.35 & 88.28 \\
\hline Negate & 3.21 & 0.92 & 0.56 & 0.95 & 0.77 & 0.39 \\
\hline Number & 1.93 & 1.85 & 3.20 & 2.85 & 4.63 & 2.56 \\
\hline Posemo & 3.00 & 5.54 & 3.69 & 3.53 & 5.79 & 4.22 \\
\hline Negemo & 2.78 & 0.00 & 0.53 & 0.41 & 0.19 & 0.54 \\
\hline Anx & 0.00 & 0.00 & 0.06 & 0.00 & 0.00 & 0.00 \\
\hline Anger & 0.43 & 0.00 & 0.08 & 0.00 & 0.19 & 0.00 \\
\hline Sad & 1.71 & 0.00 & 0.17 & 0.14 & 0.00 & 0.39 \\
\hline Insight & 2.78 & 2.08 & 2.79 & 2.58 & 3.28 & 2.52 \\
\hline Tentat & 3.85 & 2.54 & 1.82 & 1.49 & 3.47 & 1.55 \\
\hline Power & 2.36 & 2.77 & 3.88 & 1.90 & 1.54 & 3.83 \\
\hline Reward & 1.28 & 0.23 & 1.21 & 1.22 & 2.32 & 1.74 \\
\hline Risk & 1.28 & 0.46 & 0.66 & 0.41 & 1.35 & 0.23 \\
\hline Focuspresent & 15.20 & 9.70 & 8.21 & 11.01 & 11.39 & 9.26 \\
\hline Focusfuture & 1.50 & 0.23 & 2.81 & 1.77 & 1.54 & 1.98 \\
\hline Money & 2.57 & 6.93 & 5.31 & 2.45 & 1.54 & 0.97 \\
\hline
\end{tabular}

*This percentage score is computed by merging all emails of the listed executives and analyzing them as a single text. For example, all emails of Fastow are merged into a single text document and then analyzed in LIWC system as one text document.

Table 3. LIWC Traits and LIWC percentage scores for Facebook's executives whose emails were released in the UK and had more than 400 words in their email messages. In the table, the highest score in each row is highlighted in blue and the lowest in red.*15

\footnotetext{
${ }^{15}$ The LIWC scores for data with less than 400 words is considered unreliable.
} 


\begin{tabular}{|c|c|c|c|c|c|}
\hline Executive & $\begin{array}{c}\text { K. } \\
\text { Papamildidas, Zuckerberg, } \\
\text { CEO } \\
\text { Director of } \\
\text { Platform } \\
\text { Partnerships }\end{array}$ & $\begin{array}{c}\text { Mark Lessin, } \\
\text { VP of } \\
\text { Product } \\
\text { Development } \\
\text { related to } \\
\text { Partnerships }\end{array}$ & $\begin{array}{c}\text { Simon } \\
\text { Cross } \\
\text { Product }\end{array}$ & $\begin{array}{c}\text { Sachin } \\
\text { Plugin } \\
\text { Monga } \\
\text { Apps }\end{array}$ & $\begin{array}{c}\text { Platform } \\
\text { Team, } \\
\text { Social } \\
\text { Media } \\
\text { Interactions }\end{array}$ \\
\hline WC & 4134 & 1774 & 7442 & 694 & 433 \\
\hline Analytic & 77.49 & 53.81 & 66.87 & 77.46 & 61.54 \\
\hline Clout & 88.34 & 83.81 & 77.41 & 93.65 & 69.43 \\
\hline Authentic & 17.46 & 36.20 & 24.73 & 6.92 & 14.11 \\
\hline Tone & 92.70 & 74.11 & 89.57 & 55.66 & 86.05 \\
\hline Negate & 1.04 & 2.20 & 1.53 & 0.58 & 2.08 \\
\hline Number & 1.31 & 1.52 & 1.24 & 1.15 & 2.31 \\
\hline Posemo & 4.43 & 3.61 & 4.42 & 2.45 & 3.70 \\
\hline Negemo & 0.22 & 1.01 & 0.60 & 0.86 & 0.23 \\
\hline Anx & 0.10 & 0.39 & 0.13 & 0.43 & 0.23 \\
\hline Anger & 0.00 & 0.28 & 0.12 & 0.43 & 0.00 \\
\hline Sad & 0.07 & 0.11 & 0.17 & 0.14 & 0.00 \\
\hline Insight & 2.56 & 3.27 & 3.18 & 0.86 & 2.77 \\
\hline Tentat & 3.29 & 4.68 & 3.29 & 2.59 & 2.54 \\
\hline Power & 1.89 & 1.47 & 2.31 & 2.88 & 3.46 \\
\hline Reward & 1.28 & 2.03 & 2.02 & 2.16 & 1.62 \\
\hline Risk & 0.31 & 0.45 & 0.28 & 0.43 & 0.23 \\
\hline Focuspresent & 11.13 & 13.25 & 12.34 & 14.55 & 11.32 \\
\hline Focusfuture & 1.96 & 1.58 & 1.06 & 1.73 & 1.62 \\
\hline Money & 1.26 & 3.78 & 3.13 & 0.58 & 2.08 \\
\hline
\end{tabular}

*This percentage score is computed by merging all emails of the listed executives and analyzing them as a single text. For example, all emails of Papamildidas are merged into a single text document and then analyzed in LIWC system as one text document.

Table 4: A Comparison of the Average of all LIWC percentage scores for Skilling and Zuckerberg and a determination of their statistical difference using P-Value tests of significance.* 


\begin{tabular}{|c|c|c|c|}
\hline Traits & $\begin{array}{c}\text { Average } \\
\text { Score } \\
\text { for } \\
\text { Skilling } \\
\text { Emails }\end{array}$ & $\begin{array}{c}\text { Average } \\
\text { Score for } \\
\text { Zuckerberg } \\
\text { Emails }\end{array}$ & $\begin{array}{c}\text { P- } \\
\text { Value } \\
\text { (two } \\
\text { Tail) }\end{array}$ \\
\hline WC & 2582 & 1774 & n/a \\
\hline Analytic & $\mathbf{7 7 . 5 3}$ & $\mathbf{5 6 . 9 5}$ & $\mathbf{0 . 0 3 9 2}$ \\
\hline Clout & 83.42 & 85.27 & 0.7630 \\
\hline Authentic & 29.77 & 35.02 & 0.5275 \\
\hline Tone & 76.04 & 65.38 & 0.4489 \\
\hline Negate & $\mathbf{0 . 2 3}$ & $\mathbf{1 . 7 9}$ & $\mathbf{0 . 0 2 6 6}$ \\
\hline Number & 2.46 & 0.91 & 0.0536 \\
\hline Posemo & $\mathbf{5 . 8 6}$ & $\mathbf{3 . 0 0}$ & $\mathbf{0 . 0 3 1 2}$ \\
\hline Negemo & 0.60 & 0.79 & 0.6854 \\
\hline Anx & 0.00 & 0.37 & 0.1129 \\
\hline Anger & 0.00 & 0.23 & 0.0887 \\
\hline Sad & 0.43 & 0.09 & 0.1544 \\
\hline Insight & 1.61 & 2.92 & 0.0532 \\
\hline Tentat & $\mathbf{1 . 2 9}$ & $\mathbf{4 . 9 4}$ & $\mathbf{0 . 0 0 0 1}$ \\
\hline Power & $\mathbf{4 . 5 0}$ & $\mathbf{1 . 2 0}$ & $\mathbf{0 . 0 0 2 3}$ \\
\hline Reward & 1.66 & 1.98 & 0.6194 \\
\hline Risk & 0.57 & 0.40 & 0.7181 \\
\hline Focuspresent & $\mathbf{9 . 7 5}$ & $\mathbf{1 3 . 0 5}$ & $\mathbf{0 . 0 2 3 5}$ \\
\hline Focusfuture & 1.68 & 1.33 & 0.4418 \\
\hline Money & 1.54 & 4.72 & 0.1995 \\
\hline & & & \\
\hline
\end{tabular}

*The scores reported are the average score of individual emails sent by Skilling and Zuckerberg. They are then tested for the statistical significance of the differences in the average of the scores.

Table 5: A Comparison of the Average of all LIWC percentage scores for all Enron and Facebook messages and a determination of their statistical difference using P-Value tests of significance. 


\begin{tabular}{|c|c|c|c|}
\hline Traits & $\begin{array}{c}\text { Average } \\
\text { Score } \\
\text { for } \\
\text { Enron } \\
\text { Emails }\end{array}$ & $\begin{array}{c}\text { Average } \\
\text { Score for } \\
\text { Facebook } \\
\text { Emails }\end{array}$ & $\begin{array}{c}\text { P-Value } \\
\text { (two Tail) }\end{array}$ \\
\hline WC & 15238 & 14109 & n/a \\
\hline Analytic & 74.46 & 68.07 & 0.0761 \\
\hline Clout & $\mathbf{7 2 . 1 6}$ & $\mathbf{8 0 . 0 3}$ & $\mathbf{0 . 0 2 3 1}$ \\
\hline Authentic & 30.52 & 23.35 & 0.0656 \\
\hline Tone & 72.73 & 80.87 & 0.0558 \\
\hline Negate & 1.00 & 0.98 & 0.9326 \\
\hline Number & 2.10 & 1.31 & 0.0522 \\
\hline Posemo & 5.13 & 5.27 & 0.8688 \\
\hline Negemo & $\mathbf{0 . 5 4}$ & $\mathbf{0 . 2 6}$ & $\mathbf{0 . 0 2 2 1}$ \\
\hline Anx & 0.04 & 0.10 & 0.2039 \\
\hline Anger & 0.05 & 0.08 & 0.6449 \\
\hline Sad & $\mathbf{0 . 2 4}$ & $\mathbf{0 . 0 5}$ & $\mathbf{0 . 0 1 5 3}$ \\
\hline Insight & 2.15 & 2.46 & 0.3156 \\
\hline Tentat & $\mathbf{2 . 0 2}$ & $\mathbf{3 . 7 9}$ & $\mathbf{0 . 0 0 1 6}$ \\
\hline Power & $\mathbf{3 . 0 4}$ & $\mathbf{1 . 9 1}$ & $\mathbf{0 . 0 1 5 2}$ \\
\hline Reward & 1.16 & 1.77 & 0.1058 \\
\hline Risk & $\mathbf{0 . 5 4}$ & $\mathbf{0 . 2 2}$ & $\mathbf{0 . 0 2 3 1}$ \\
\hline focuspresent & $\mathbf{1 1 . 0 5}$ & $\mathbf{1 2 . 9 7}$ & $\mathbf{0 . 0 3 8 7}$ \\
\hline focusfuture & 1.77 & 1.87 & 0.7555 \\
\hline Money & $\mathbf{2 . 8 9}$ & $\mathbf{1 . 2 5}$ & $\mathbf{0 . 0 0 0 1}$ \\
\hline & & & \\
\hline
\end{tabular}

*The scores reported are the average scores of the individual emails sent by Enron and Facebook executives. They are then tested for the statistical significance of differences in the average of the scores.

Table 6: A Comparison of the Average of all LIWC percentage scores for Fastow and Lay and a determination of their statistical difference using P-Value tests of significance.* 


\begin{tabular}{|c|c|c|c|}
\hline Traits & $\begin{array}{c}\text { Average Score } \\
\text { for Fastow } \\
\text { Emails }\end{array}$ & $\begin{array}{c}\text { Average Score } \\
\text { for Lay Emails }\end{array}$ & $\begin{array}{c}\text { P-Value } \\
\text { (two Tail) }\end{array}$ \\
\hline WC & $\mathbf{4 6 7}$ & $\mathbf{1 0 5 0 2}$ & n/a \\
\hline Analytic & $\mathbf{5 1 . 2 9}$ & $\mathbf{8 0 . 6 9}$ & $\mathbf{0 . 0 0 0 0}$ \\
\hline Clout & $\mathbf{4 3 . 7 2}$ & $\mathbf{8 3 . 6 5}$ & $\mathbf{0 . 0 0 0 2}$ \\
\hline Authentic & $\mathbf{4 6 . 6 6}$ & $\mathbf{2 4 . 1 5}$ & $\mathbf{0 . 0 2 6 3}$ \\
\hline Tone & $\mathbf{4 2 . 5 4}$ & $\mathbf{7 4 . 0 9}$ & $\mathbf{0 . 0 1 9 6}$ \\
\hline Negate & $\mathbf{3 . 6 3}$ & $\mathbf{0 . 6 1}$ & $\mathbf{0 . 0 0 2 8}$ \\
\hline Number & 1.32 & 2.14 & 0.2451 \\
\hline Posemo & 2.43 & 5.54 & 0.1168 \\
\hline Negemo & 1.54 & 0.57 & 0.1970 \\
\hline Anx & $\mathbf{0 . 0 0}$ & $\mathbf{0 . 1 3}$ & $\mathbf{0 . 0 2 4 2}$ \\
\hline Anger & 0.26 & 0.04 & 0.2359 \\
\hline Sad & 0.79 & 0.17 & 0.2598 \\
\hline Insight & 1.65 & 2.36 & 0.4091 \\
\hline Tentat & $\mathbf{4 . 8 3}$ & $\mathbf{1 . 5 4}$ & $\mathbf{0 . 0 4 9 7}$ \\
\hline Power & $\mathbf{1 . 6 4}$ & $\mathbf{3 . 7 2}$ & $\mathbf{0 . 0 3 3 0}$ \\
\hline Reward & 1.70 & 1.06 & 0.6070 \\
\hline Risk & 0.71 & 0.57 & 0.7057 \\
\hline Focuspresent & $\mathbf{1 6 . 5 5}$ & $\mathbf{1 0 . 3 6}$ & $\mathbf{0 . 0 2 0 0}$ \\
\hline Focusfuture & $\mathbf{1 . 0 4}$ & $\mathbf{2 . 3 0}$ & $\mathbf{0 . 0 0 9 4}$ \\
\hline Money & 3.22 & 3.97 & 0.5644 \\
\hline
\end{tabular}

*The percentage scores are the average score of individual emails sent by Fastow and Lay. They are then tested for the statistical significance of differences in the average of the scores.

Table 7. A Comparison of the Average of all LIWC percentage scores for Fastow and Skilling and a determination of their statistical difference using P-Value tests of significance.* 


\begin{tabular}{|c|c|c|c|}
\hline Traits & $\begin{array}{c}\text { Average Score } \\
\text { for Fastow } \\
\text { Emails }\end{array}$ & $\begin{array}{c}\text { Average Score } \\
\text { for Skilling } \\
\text { Emails }\end{array}$ & $\begin{array}{c}\text { P-Value } \\
\text { (two Tail) }\end{array}$ \\
\hline WC & $\mathbf{4 6 7}$ & $\mathbf{2 5 2 8}$ & n/a \\
\hline Analytic & $\mathbf{5 1 . 2 9}$ & $\mathbf{7 7 . 5 3}$ & $\mathbf{0 . 0 0 2 1}$ \\
\hline Clout & $\mathbf{4 3 . 7 2}$ & $\mathbf{8 3 . 4 2}$ & $\mathbf{0 . 0 0 0 2}$ \\
\hline Authentic & 46.66 & 29.77 & 0.1403 \\
\hline Tone & $\mathbf{4 2 . 5 4}$ & $\mathbf{7 6 . 0 4}$ & $\mathbf{0 . 0 2 4 9}$ \\
\hline Negate & $\mathbf{3 . 6 3}$ & $\mathbf{0 . 2 3}$ & $\mathbf{0 . 0 0 0 8}$ \\
\hline Number & 1.32 & 2.46 & 0.1574 \\
\hline Posemo & $\mathbf{2 . 4 3}$ & $\mathbf{5 . 8 6}$ & $\mathbf{0 . 0 2 7 6}$ \\
\hline Negemo & 1.54 & 0.60 & 0.2304 \\
\hline Anx & 0.00 & 0.00 & - \\
\hline Anger & 0.26 & 0.00 & 0.1574 \\
\hline Sad & 0.79 & 0.43 & 0.5371 \\
\hline Insight & 1.65 & 1.61 & 0.9657 \\
\hline Tentat & $\mathbf{4 . 8 3}$ & $\mathbf{1 . 2 9}$ & $\mathbf{0 . 0 3 5 7}$ \\
\hline Power & $\mathbf{1 . 6 4}$ & $\mathbf{4 . 5 0}$ & $\mathbf{0 . 0 1 9 6}$ \\
\hline Reward & 1.70 & 1.66 & 0.9808 \\
\hline Risk & 0.71 & 0.57 & 0.7878 \\
\hline Focuspresent & $\mathbf{1 6 . 5 5}$ & $\mathbf{9 . 7 5}$ & $\mathbf{0 . 0 0 3 7}$ \\
\hline Focusfuture & 1.04 & 1.68 & 0.2558 \\
\hline Money & 3.22 & 1.54 & 0.2558 \\
\hline
\end{tabular}

*The percentage scores reported are the average score of individual emails sent by Fastow and Skilling. They were then tested for the statistical significance of differences in the average of the scores. 